\title{
Optimising the Benefits from Research Institutes
}

\author{
Thierry Lagrange
}

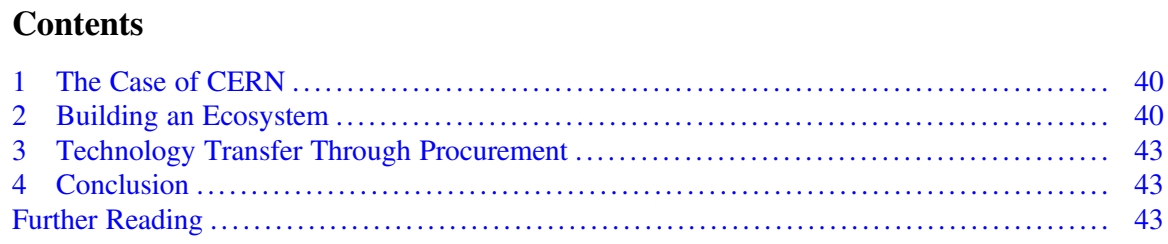

Today, a large number of public research institutes have been set up in many different fields to carry out scientific research. The initial financial investment needed was generally justified by the pure scientific interest. As the number and size of these research institutes has grown over time, the associated investments have become quite substantial. The will to push the frontier of knowledge implies developing and upgrading high-tech instruments, working with cutting-edge technologies, and high maintenance costs, which requires additional public spending. As the available public resources have not evolved at the same rate as scientific ambitions, competition between scientific fields and projects has become fiercer as well as the need for additional arguments to justify these investments.

The pressure to show the potential social benefits beyond the scientific case have therefore intensified, making it increasingly difficult for projects to get funding or remain financially sustainable without socio-economic justifications.

Each research field is different and the socio-economic benefits can vary widely from one field to another. The nature of the research, whether it is fundamental or applied research, whether the instruments used require vast financial investment or not, and whether breakthrough technology is required or not will result in different socio-economic benefits.

\footnotetext{
T. Lagrange (殴)

Procurement \& Knowledge Transfer Department, CERN, Geneva, Switzerland e-mail: Thierry.Lagrange@cern.ch 


\section{The Case of CERN}

CERN exists to carry out fundamental research in high energy physics. Its activities necessitate large investments, breakthrough technologies, periodic upgrades and maintenance. The socio-economic benefits are multiple: training of scientists and engineers, outreach and education, development of innovative technologies and collaboration with industry, to name just a few. The scientific justification and the fact that fundamental science is indispensable for applied research is not disputed, but funding institutes expect that all other possible benefits be optimised too.

The challenge, therefore, is understanding how to accelerate and optimise the generation of these benefits. It is clear that time is of essence: the sooner society can benefit from spin-offs generated by research institutes, the bigger the impact will be on further research funding and on global growth. At the same time, most of the technologies developed in connection with CERN's equipment and operations have too low a technology readiness level (TRL) to trigger the immediate interest of private capital or big institutional investors. For this reason, the process of bringing CERN's innovation to society is seldom spontaneous and direct. In order to be effective and systematic, the research institute itself needs to actively engineer improvements in the TRL, supported by public funding, until it is sufficient to attract external capital.

\section{Building an Ecosystem}

Building a proper ecosystem is an indispensable prerequisite to transferring knowledge and technologies to society in a way that maximizes the socio-economic benefits. Such an ecosystem thrives with the generation of innovative, preferably breakthrough, technologies, resources to increase the TRL, a fit-for-purpose IP policy and governance, access to a network of technology brokers, incubators, venture capitalist and policy makers, and the active support of the scientist or engineer at the origin of the innovation. The involvement of knowledge transfer experts is also essential. The CERN Knowledge Transfer group provides advice, support, training, networks and infrastructure to ease the transfer of CERN's knowhow to industry and to society. 


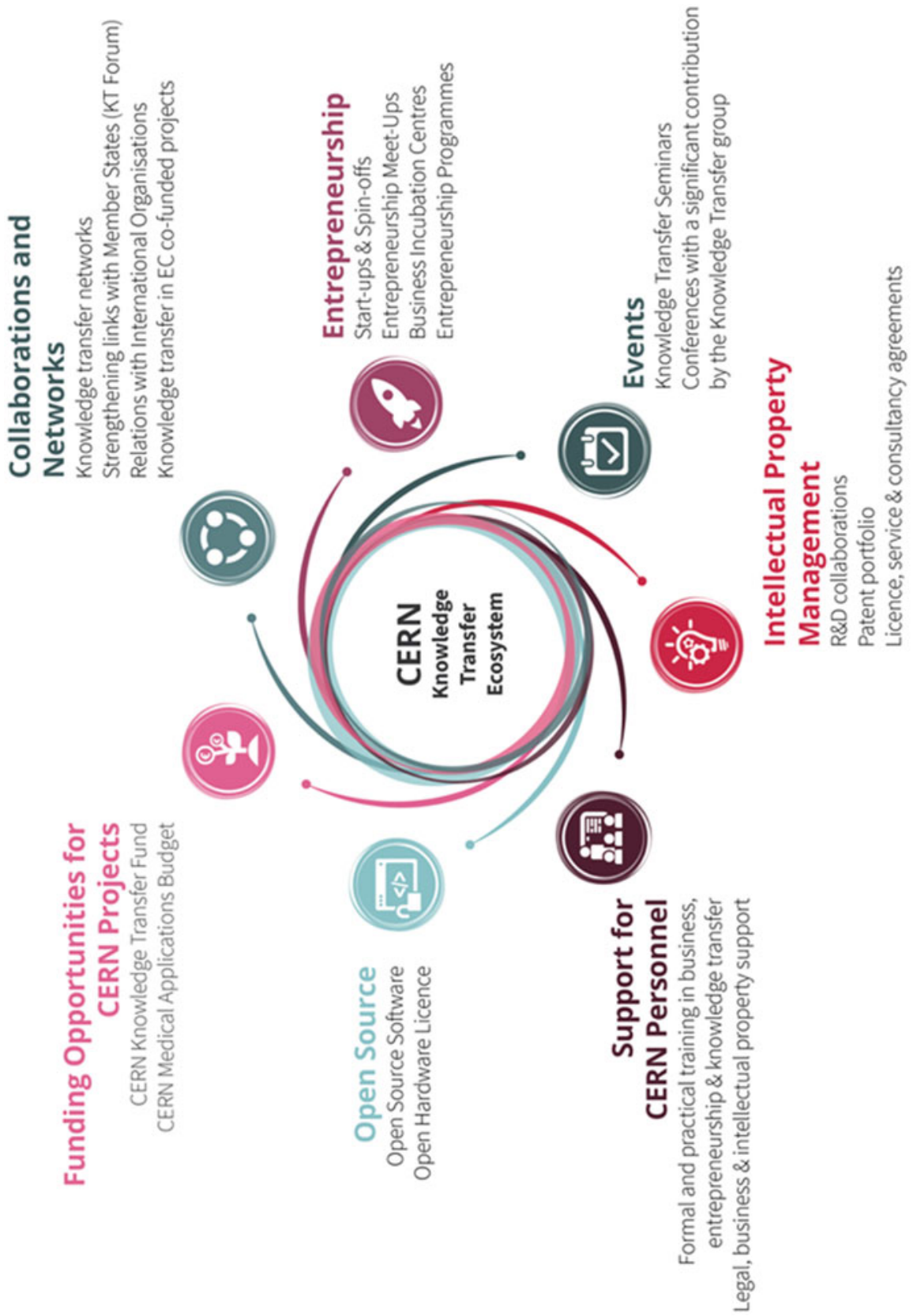


Similar to other institutes, CERN has created a business incubator network. This involves CERN signing agreements with existing incubators in its Member States to facilitate the creation of start-ups based on CERN technologies. The incubators promote CERN's technologies and give the start-ups access to their full range of support services. In return, CERN makes available to the start-up the necessary IP and initial technical support, plus the right to use CERN's branding.

It should be noted that for scientists and engineers behind the technologies developed at CERN, identifying industries or sectors where those technologies could be best applied is far from straightforward. For this reason, CERN has increased its contacts with early-stage venture capital firms. These firms bring a complementary perspective: they typically start from 'real life' so-called 'pains' in domains such as health and transport, determine the limitations of the existing technologies, and then search for technologies that can bring solutions to wellidentified problems.

Large companies also face similar problems and some are looking for solutions (or for help to find solutions) in academia. A key factor for successful technology transfer is identifying an industry problem that can be addressed by the technologies and competences of research institutions (market pull), as opposed to simply pushing technologies which have been developed to solve specific research-related problems (technology push). Finding this match between industry and research is often a recursive process. Discussions often take place with several companies before a good match is found with some of them.

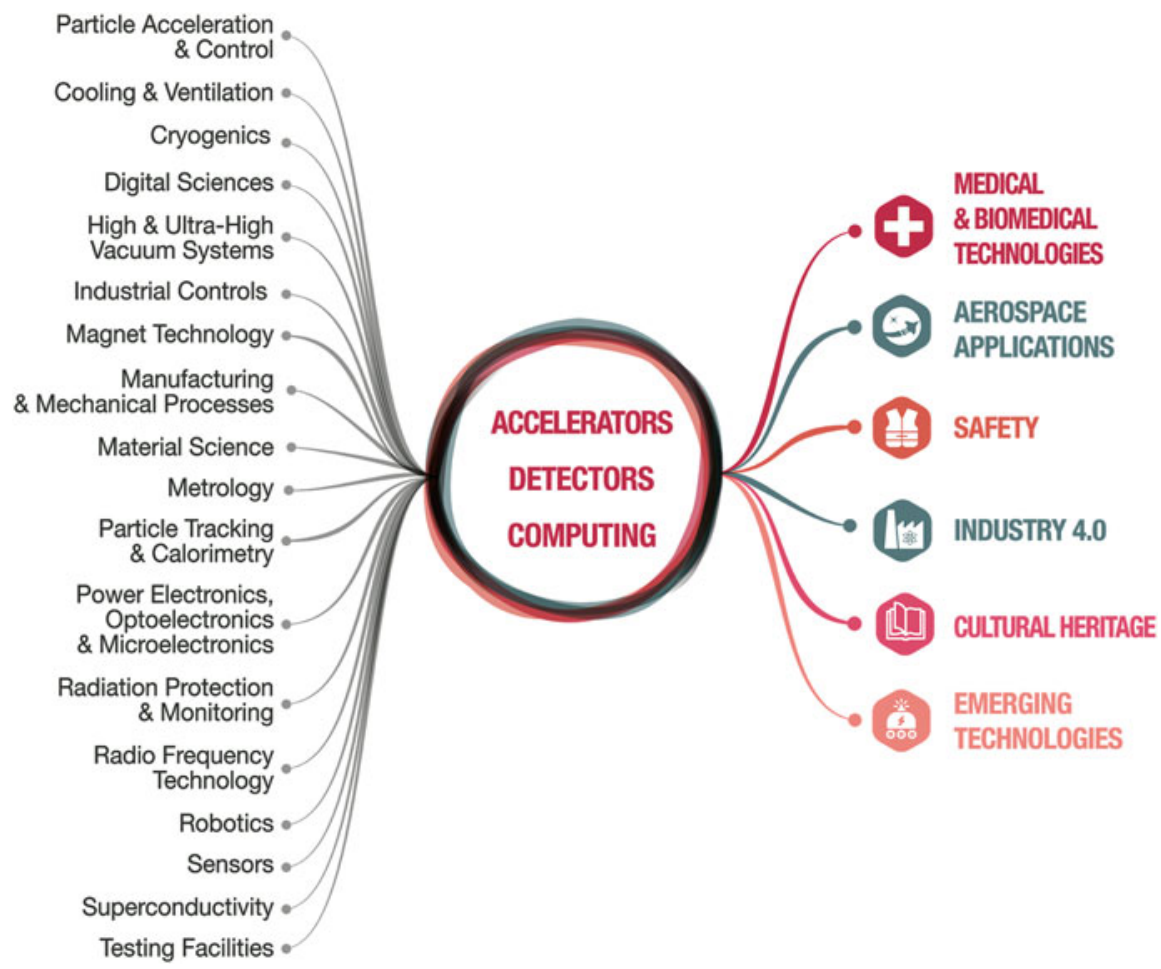




\section{Technology Transfer Through Procurement}

When discussing the socio-economic impact of big science centres one cannot ignore the role of procurement in constructing, operating and maintaining the sophisticated scientific tools but also for meeting the needs of thousands of researchers from around the world that use CERN's infrastructure for their research.

CERN has an average annual expenditure on goods and services of 500 million Swiss francs. Among other things, CERN procures civil, mechanical and electrical engineering, information technology, radiofrequency, cryogenics and vacuum as well as detector technologies. When the Organization needs to buy innovative equipment, it has the option of either doing the development itself and subcontracting the series manufacturing, or entrusting industry with the whole process from design to production.

In order to reduce the cost and risk associated with high-tech innovative equipment for which CERN has established know-how and expertise, the development phase is often done in-house. The contract for the series production is then based on a build-to-print specification written by CERN. It is at this stage that the technology transfer happens from CERN to the industry. On its side, industry brings the expertise and know-how needed to scale a prototype operation into a series production.

For firms, this technology transfer can result in the development of new products, improved products or services, better technical knowledge in their field and the ability to reach new markets. After working with CERN, companies often invest more in $R \& D$, file more patents and exhibit higher levels of productivity.

\section{Conclusion}

Literature and studies confirm the high socio-economical potential benefits from research institutes to society. These benefits are not generated automatically, they require a process that includes the selection of the most promising technologies to the support to bring to maturity the technology to the market. This support can take many different shapes according to the needs. Which IP, which resources, what kind of network, which skills are required, this varies case by case, but to be successful, all of them must be covered.

\section{Further Reading}

1. CERN KT's 2019 Annual Report: https://kt.cern/about-us/annual-report

2. Impact of CERN's Procurement Actions on Industry: 28 illustrative stories (CERN, 2019): https://cds.cern.ch/record/2670056

3. CERN's 2018 Annual Report: https://cds.cern.ch/record/2671714? ln=en 
Open Access This chapter is licensed under the terms of the Creative Commons Attribution 4.0 International License (http://creativecommons.org/licenses/by/4.0/), which permits use, sharing, adaptation, distribution and reproduction in any medium or format, as long as you give appropriate credit to the original author(s) and the source, provide a link to the Creative Commons licence and indicate if changes were made.

The images or other third party material in this chapter are included in the chapter's Creative Commons licence, unless indicated otherwise in a credit line to the material. If material is not included in the chapter's Creative Commons licence and your intended use is not permitted by statutory regulation or exceeds the permitted use, you will need to obtain permission directly from the copyright holder. 